\title{
Research Paper: Evaluation of Functional Preparedness and Non Structural Safety of Different Health Units of crossuark Kermanshah University of Medical Sciences in Coping With Natural Disasters
}

\author{
Abdollah Dargahi', Mehrdad Farrokhi², Mohsen Poursadeghiyan², Mir Mohammad Hossein Ahagh ${ }^{3}$, Amir Karami ${ }^{4 *}$
}

1. Department of Environmental Health Engineering, School of Health, Hamadan University of Medical Sciences, Hamadan, Iran.

2. Research Center in Emergency and Disaster Health, University of Social Welfare and Rehabilitation Sciences, Tehran, Iran.

3. Department of Public Health, Khalkhal School of Medicine, Ardabil University of Medical sciences, Ardabil, Iran.

4. Department of Environmental Health Engineering, Faculty of Public Health, Kermanshah University of Medical Sciences, Kermanshah, Iran.

\begin{tabular}{|c|c|}
\hline $\begin{array}{l}\text { Usuevourdevive etoscan } \\
\text { and read the article online }\end{array}$ & Ciffation: Dargahi A. Farrokhi M. Poursadeghivan M. Ahagh MMH. Karami A. Evaluation of Functional Preparedness and \\
\hline$\square 8 \square$ & Non Structural Safety of Different Health Units of Kermanshah University of Medical Sciences in Coping With Natural Disas- \\
\hline T. & ters. Health in Emergencies and Disasters Quarterly. 2017; 2(4):201-206. \\
\hline 口4:4: & doi: : ??? \\
\hline
\end{tabular}

Article info:

Received: 19 Jan. 2017

Accepted: 13 Apr. 2017

\section{Keywords:}

Emergency preparedness, Safety, Crisis, Health facilities, Natural disasters

\begin{abstract}
A B S T R A C T
Background: Every year, accidents and disasters occur in Iran and result in death and injuries of common people. People's demand for health care units involves not only the requirement for medical centers but also staffs to work in them. Therefore, the purpose of this study is to investigate the performance readiness and non-structural functional safety of different health care centers and units of Kermanshah University of Medical Sciences in dealing with natural disasters.

Materials and Methods: This is a cross-sectional descriptive and analytical study conducted in connection with the non-structural safety status of 837 health care centers and facilities at the headquarters of Kermanshah University of Medical Sciences in 2015. Established checklists were distributed among 24 assessment teams and completed by trained experts after assessing the status quo of the health units with relevance to the checklist.

Results: The results showed that in terms of natural hazards, the highest and lowest likelihood of occurrences were related to earthquake $(75 \%)$ and landslide (20\%), respectively. In the field of functional readiness of health units and various other departments at the headquarters of health centers, fire extinguishing section had the highest percentage of readiness with $68 \%$. However, the risk reduction measures and health insurance coverage had the lowest percentage of readiness in responding to disasters with $3 \%$ and $0 \%$, respectively. The non-structural sanitary homes recorded $48 \%$ of readiness, whereas the network headquarters and health centers recorded $35 \%$ of readiness, which denoted the highest and lowest rate in the context of vulnerability, respectively.
\end{abstract}

Conclusion: In general, the results showed that the average performance percentage and non-structural vulnerability of health units and various other departments are moderate at the headquarters of health centers. According to the study results, disasters like earthquake, dust, flood, and landslide frequently required preparedness in the whole region.

\section{* Corresponding Author:}

Amir Karami, MSc.

Address: Department of Environmental Health Engineering, Faculty of Public Health, Kermanshah University of Medical Sciences, Kermanshah, Iran E-mail: amir_karami119@yahoo.com 


\section{Introduction}

$\mathbf{D}$

isasters and accidents occur when the equipment and facilities needed to lead a normal life fail to perform their usual functions. The destructive and devastating impacts of sudden incidents or natural calamities reduce the ability of a community to meet the needs and demands of health care. At times, such incidents also cause injuries, leading to disability or loss of life [1]. Natural disasters of varying intensities often occur in Iran, and the possibility of their occurrence is felt differently in different societies $[2,3]$. The consequences also include damages caused to both life and property.

Iran is one of the 10 most vulnerable countries in the world. According to statistics, 31 out of 40 natural disasters have occurred in Iran, and there is a likelihood of occurrence of disasters in future [4-6]. According to the International Federations of Red Crescent Societies and Red Cross in 2002, disasters have affected nearly 170 million people around the world causing loss to both life and property. The WHO stated that around 5 million people worldwide lose their lives annually and many suffer from disability after the incidents [7]. Moreover, over the past century, 81 major incidents have occurred in Iran that claimed the lives of 160,000 people, and injured more than 44 million people [8]. These figures express a kind of warning, citing the need of having a strategic plan to deal with future disasters. It is evident from past experiences that whenever an individual is prepared for an accident or disaster, he/she can control the situation in a better way. Therefore, designing appropriate strategies and plans in countries like Iran is essential to cope with critical situations and reduce both physical and financial losses $[9,10]$.

In such incidents and disasters, hospitals and health care units with timely health services play a decisive role in controlling the aftermath including the rescue of injured people and casualties [11, 12]. Moreover, implementing efficient management strategies in these health centers before the onset of a crisis has a significant impact on their desired and optimal performance [7]. The lack of such plans and strategic measures may cause irreparable damage to the healthcare system of the country [13]. Considering the importance of preparedness in health care system for dealing with disasters and unexpected events, this study aimed at evaluating the functional readiness and non-structural safety of health centers and units in the Kermanshah University of Medical Sciences. This study also intends to obtain the necessary information required for better planning by health care executives in future.

\section{Materials and Methods}

This is a cross-sectional descriptive and analytical study in connection with the non-structural safety status of 837 health care centers and facilities as well as sanitary homes (14 Headquarters of Network Center and Health Center, 67 urban health centers, 61 rural health centers, 29 health centers, and 652 rural sanitary homes) in Kermanshah University of Medical Sciences in 2015. Established checklists were distributed among 24 assessment teams and completed by trained experts after viewing the status quo and analyzing its match with the checklists. At first, the detailed statistical report of health centers and facilities of the province were received from the headquarters of each city. In every city, three people including the head of the health center, environmental health expert, and the expert dealing with expansion strategies received necessary training on how to complete the Disaster Risk Assessment Checklist.

The results derived from the completed checklists assessed the threats of the centers (Question 48), functional preparation of the health systems (Question 236), and vulnerability of the checklist (Question 5). In non-structural vulnerability, separate checklists were completed and collected to investigate the city-wise status of each subset of network headquarters and health centers, urban and rural health centers, health centers and sanitary homes. The collected information was analyzed by using the Excel software.

\section{Results}

In terms of natural hazards like earthquake, dust, and flood, the probabilities of occurrences are $75 \%, 68 \%$, and $42 \%$ per year, respectively. On the other hand, the probability of occurrence of lightning and landslide is comparatively less with only $27 \%$ and $20 \%$ per year, respectively. In terms of functional readiness of health care units and other departments at the headquarters of health centers, fire extinguishing section had the highest rate of readiness with $68 \%$, environmental health with $58 \%$, exercise and maneuvering with $54 \%$, and commanding the scene of the operation with $48 \%$. In addition, nutrition was found to be $15 \%$, mental health of employees and their families was $10 \%$, security was $7 \%$, risk reduction measures was $3 \%$, and health insurance coverage in dealing with disasters was recorded having the lowest rate of readiness with $0 \%$.

Moreover, the percentage of functional readiness in dealing with disasters were also obtained from parameters like storing personal protective equipment and supplies 


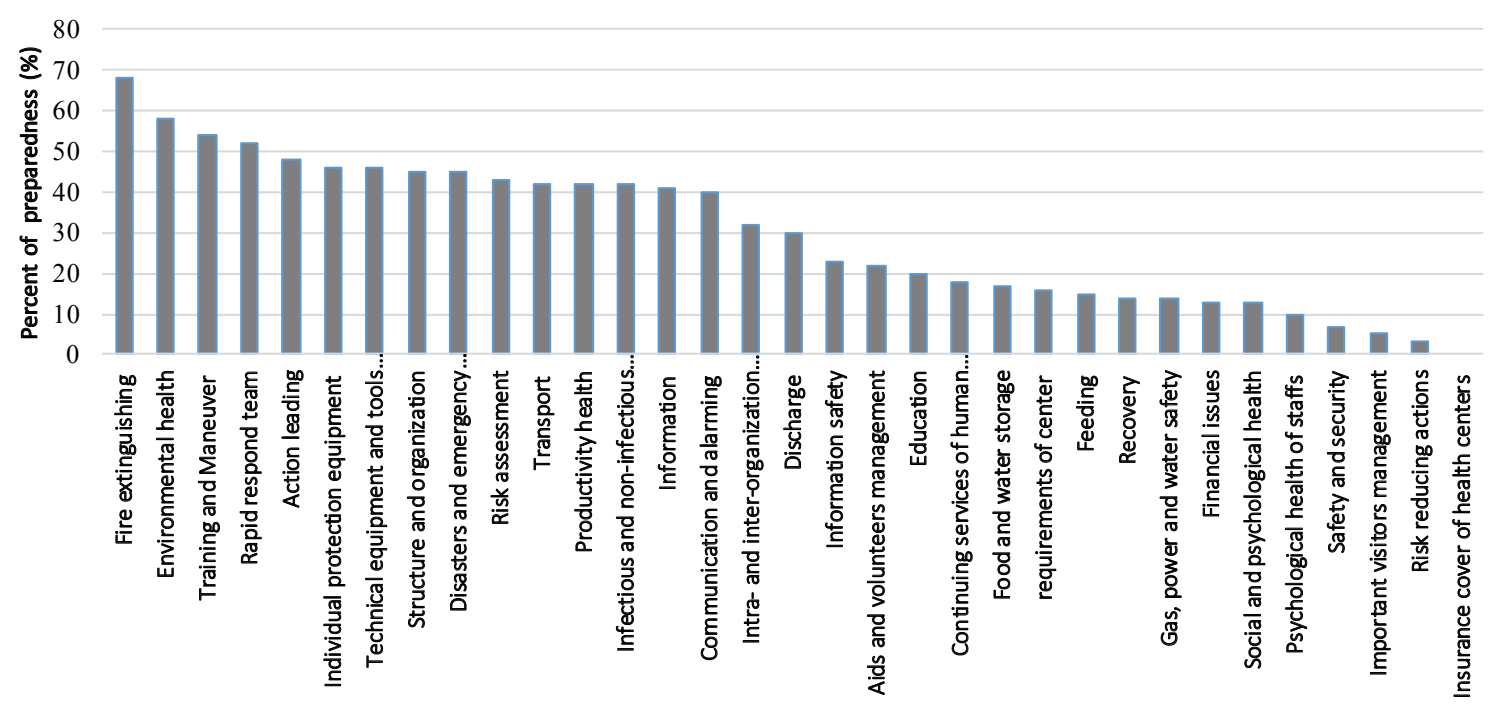

Hitealth in

Emergencies and |D]isasters [Oluarterly

Figure 1. Functional preparation of various health sectors in the headquarters of health centers of Kermanshah University of Medical Sciences

$(46 \%)$, organizations or structure for disasters and emergencies (45\%), risk assessment (43\%), transportation, reproductive health, and infectious and non-communicable diseases (42\%), internal and external coordination (32\%), and water and food supply (17\%) (Figure 1).

In terms of functional readiness of health centers and facilities in dealing with natural disasters, headquarters of health centers in cities had the highest rate of readiness with $25 \%$, urban health centers with $18.7 \%$, rural health centers with $15 \%$, health centers with $13.2 \%$, and sanitary homes had the least functional readiness with $11.5 \%$. In the non-structural vulnerability section, the functional impairment in providing health care services at the time of crisis had the highest rate of readiness with $48 \%$ and the availability of health facilities like pharmacy and dressing rooms was the lowest with only $15 \%$ (Figure 2 ).

In the context of non-structural vulnerability, sanitary homes were recorded with $48 \%$ and the network headquarters along with health centers with $35 \%$. Moreover, the percentages of non-structural vulnerability for rural,

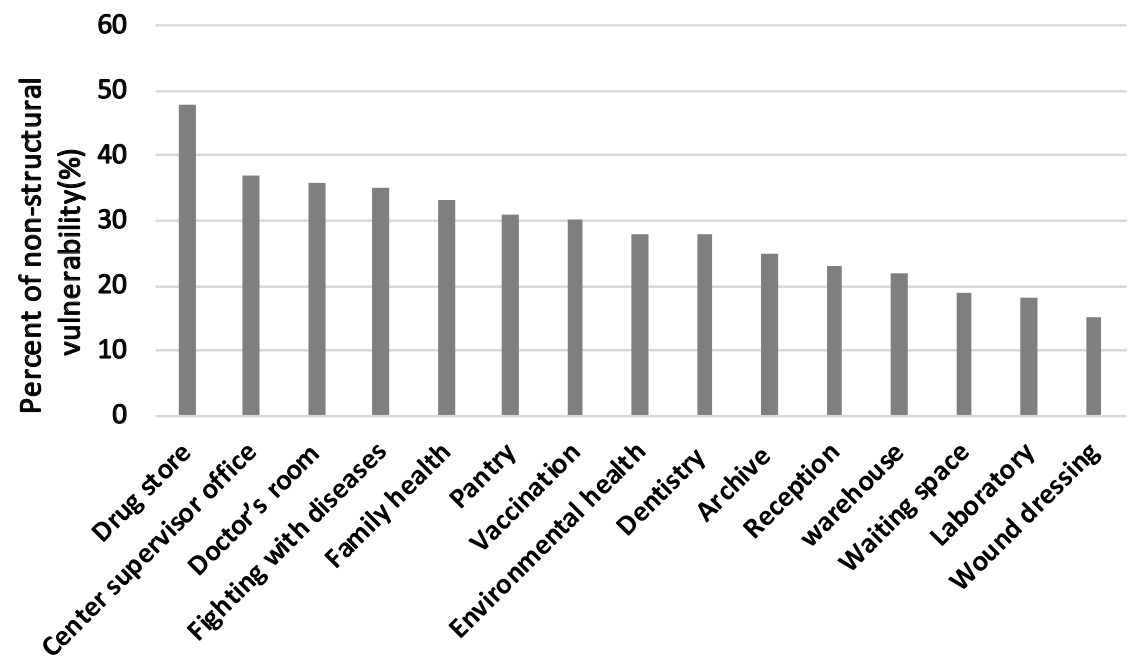

Hlealth in

Emergencies and |Disasters [O]uarterly

Figure 2. Unauthorized vulnerability of various health units in headquarters and health centers of Kermanshah University of Medical Sciences 


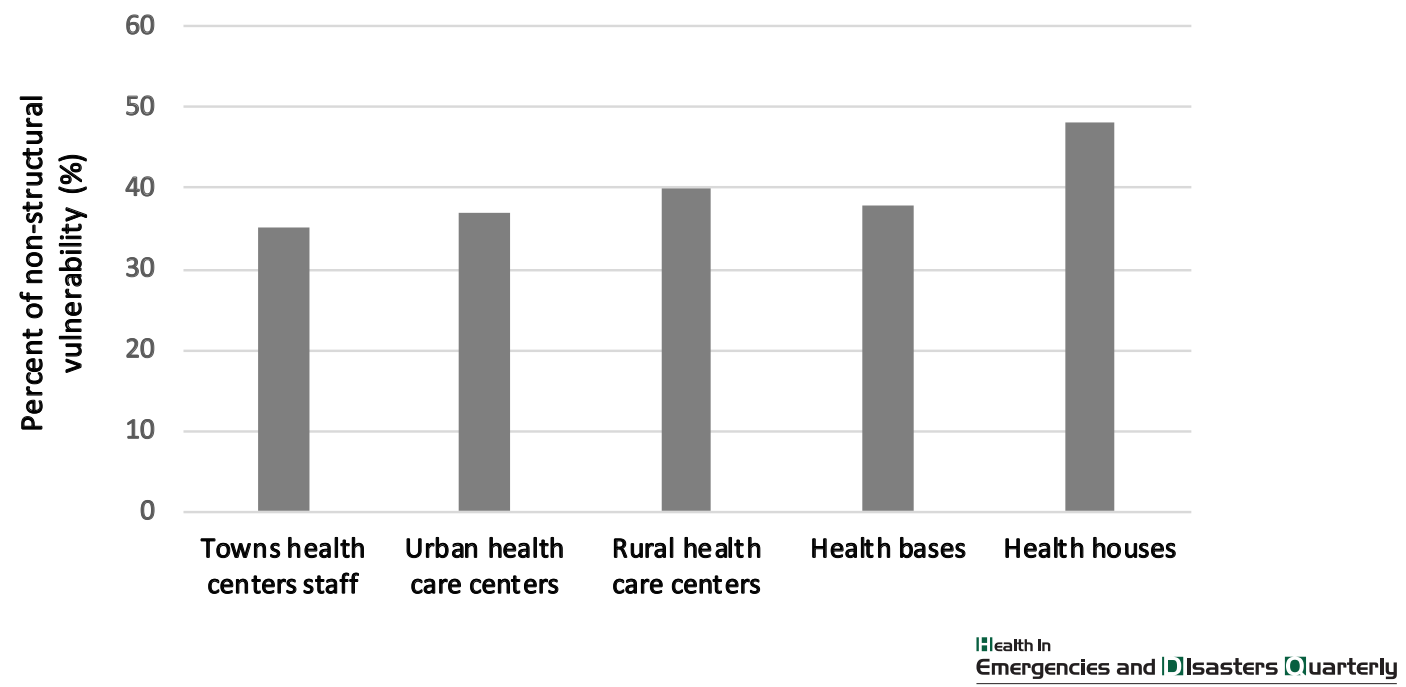

Figure 3. Overall non-structural vulnerability in health facilities of Kermanshah University of Medical Sciences

urban health centers, and health quarters were found to be $40 \%, 37 \%$, and $38 \%$, respectively (Figure 3).

\section{Discussion}

The results of this study showed that the average nonstructural vulnerability of disaster recovery facilities was $41.5 \%$, and the average preparedness of the health facility in response to disasters was $18.3 \%$. The results of the study conducted by Amerian et al. [5] showed that the preparedness of hospitals to deal with crisis was over $70 \%$. In addition, Arab et al. [11] concluded from his study in Tehran hospitals that the functional readiness of hospitals in terms of disaster response was $51 \%$ [11]. Both the studies recorded a higher percentage of readiness compared to the present study. However, Ojaghi et al. [13] found that the readiness of educational hospitals in dealing with crisis was very weak.

According to a study conducted in Jordan, $65 \%$ of nurses said that the readiness level of hospitals to deal with disasters is very low [14]. The results of the study of Al Khalaileh et al. [14] showed that Jordanian hospitals had poor readiness against disasters. Mahbub et al. [15] reported that the average readiness of three hospitals and health centers in Kermanshah in terms of equipment and facilities was $74.6 \%$, which is higher compared to the present study According to the results of functional preparedness of the health units, the low score of insurance coverage at the time of disasters in the investigated centers needs attention, as it causes many social and psychological problems to the affected people. It is also found that both internal and external factors influence the crisis management strategies during the disasters. On the whole, identifying the success or failure of an organization can be effective during crisis management [16]

In the study of Sokhanvar et al. (2015), the average risk score for health centers in South of Tehran was estimated to be $98 \%$. It concluded that the highest degree of disaster preparedness was related to the fire department and the least preparedness was related to insurance coverage and administrative units [17]. It seems that the existence of skilled people responsible for crisis management in fire fighting and environmental health units is the reason behind its high percentage of preparedness compared with other units. Therefore, trained people and employees in each section play a key role at the time of natural disaster. On the other hand, the presence of unskilled people in times of crisis will exacerbate its secondary effects.

Based on the opinion of the Duboulozin crisis management training programs, attention to warning signs, responding, and restoring the initial state are also important [13]. As per the findings of the present study, the greatest risk was related to earthquake and dust, which is consistent with the results of Sokhanvar et al. [17] Sternberg et al. [18], after reviewing 275 reports on natural disasters during 1971-1999, found that earthquake was the fifth highest form of disaster in terms of repeatability. In relationship with the degree of readiness of the studied centers in facing the crisis and maneuvers conducted, it was found that maneuvers are well performed. Management strategies of health care units must be designed to solve the crisis based on their standard operation processes [19].

In terms of overall non-structural vulnerability in the health facility of Kermanshah University of Medical 
Sciences, the sanitary homes in the current study had the highest vulnerability and the headquarters of the county health centers had the least vulnerability, which is consistent with the reports of National Center for Health Safety Assessment in dealing with disasters [20]. According to the national report, health centers and the sanitary homes recorded the highest percentage in terms of non-structural safety with $36.6 \%$ and $35.9 \%$, respectively.

\section{Conclusion}

Given that the cities of Iran, such as Kermanshah, are exposed to a variety of natural and man-made hazards, it is, therefore, necessary to be prepared with adequate health care facilities to cope with such frequent incidents and provide timely and effective help to the common people. In addition, continuous training and annual maneuvers can be effective in assessing and improving the quality of crisis management, provided that training is not limited to mere holding a workshop and conference. The health centers should also work according to the training and be prepared for an upcoming crisis.

\section{Acknowledgments}

This research did not receive any specific grant from funding agencies in the public, commercial, or not-forprofit sectors. Authors express their gratitude and appreciation towards the Department of Health and Environmental Health colleagues in the health centers of Kermanshah University of Medical Sciences.

\section{Conflict of Interest}

The authors declared no conflicts of interest.

\section{References}

[1] Nivolianitiou Z, Synodinou B. Towards emergency management of natural disasters and critical accidents: The Greek experience. Journal of Environmental Management. 2011; 92(10):2657-65. doi: 10.1016/j.jenvman.2011.06.003

[2] Pazoki A. Medical planning to deal with disaster. Paper presented at: The First Congress of Health and Crisis Management in the Event of Unexpected. 27-29 May 2003; Tehran, Iran.

[3] Daneshmandi M, Nezamzadeh M, Zareiyan A. Assessment the preparedness of selected hospital to deal with disasters in Tehran. Military Caring Sciences. 2014; 1(1):28-35. doi: 10.18869/acadpub.mcs.1.1.28
[4] Farrokhi M, Dolatabadi ZA, Pakjouei S, Pouyesh V. Review paper: Approaches to post-disaster environmental recovery. Health in Emergencies and Disasters. 2016; 1(2):65-70.

[5] Amerion A, Delaavari AR, Teymourzadeh E. Rate of preparedness in confronting crisis in three selected border hospitals. Iranian Journal of Military Medicine. 2010; 12(1):19-22

[6] Seyedin H, Abbasi Dolatabadi Z, Rajabifard F. Emergency nurses requirements' for disaster preparedness. Trauma Monthly. 2015; 20(4):e29033. doi: 10.5812/traumamon.29033

[7] Amiri M, Mohammadi Gh, Chaman R, Arabi M, Sadeghi E, Kalatejari M. [Hospital preparedness of Semnan province to deal with disasters (Persian)]. Knowledge \& Health. 2011; 6(3):44-50

[8] Hajizadeh M, Mazhari M, Pishgooie A, Aliyari S. The effect of buddy aid education packages on the wives of military personnel awareness and attitude in the face with earth quake in 2013. Military Caring Sciences. 2014; 1(1):1-8. doi: 10.18869/ acadpub.mcs.1.1.1

[9] Jourvand R, Sadeghirad K, Golami OA, Vejdani M, Panahi R, Babaei Heydarabadi A. [Disasters preparedness of health workers in Dehloran, Iran (Persian)]. Journal of Health in the Field. 2015; 3(3):13-18.

[10] Hosseini Shokouh S, Arab M, Rahimi A, Rashidian A, Sadr Momtaz N. [Preparedness of the Iran University of Medical Sciences hospitals against earthquake (Persian)]. Journal of Public Health faculty and research Health institute. 2009; 6(3 4):61-77.

[11] Arab M, Zeraati H, Akbari Haghighi F, Ravangard R. [A study on the executive managers' knowledge and performance, and their hospitals preparedness against earthquake events and their relationships at public hospitals (affiliated by Tehran University of Medical Sciences (TUMS) 2005-2006) (Persian)]. Journal of Health Administration. 2009; 11(34):714.

[12] World Health Organization. [Rapid health assessment protocol for emergencies [S. Mamishi, I. Sharifi, Keshavarz H Persian trans]. Tehran: Ministry of Health; 2001.

[13] Ojaghi SH, Nourizadeh S, Mahboubi M, Khazaei AAR, Najafi GHA. [Disaster crisis handling preparedness level of hospital in Kermanshah (Persian)]. Journal of Kermanshah University of Medical Sciences. 2009; 13(3):267-74.

[14] Al Khalaileh MA, Bond E, Alasad JA. Jordanian nurses perceptions of their preparedness for disaster management. International Emergency Nursing. 2012; 20(1):14-23. doi: 10.1016/j.ienj.2011.01.001

[15] Mahboobi M. [Reading of content of border hospitals' readiness in Kermanshah state for confronting with board's crisis (Persian)] [MA thesis]. Tehran: Islamic Azad University; 2008.

[16] JMc Carthy JL. The evolution from risk management to patient safety - case studies from the Harvard medical system. Japan and the World Economy. 2003; 15(4):459-68. doi 10.1016/s0922-1425(03)00021-5.

[17] Bahadori M, Sokhanvar M, Mousavi S, Nejad M. A survey on hazards threatening health care centers of Tehran and their level of preparedness for encountering. International Journal of Health System and Disaster Management. 2015; 3(5):27. doi: 10.4103/2347-9019.168568 
[18] Sternberg E, Lee GC, Huard D. Counting crises: US hospital evacuations, 1971-1999. Prehospital and Disaster Medicine. 2004; 19(02):150-7. doi: 10.1017/s1049023x00001667

[19] Tseng HC, Chen TF, Chou SM. SARS: Key factors in crisis management. Journal of Nursing Research. 2005; 13(1):58-65. doi: 10.1097/00134372-200503000-00008

[20] Ardalan A, Sepehrvand N, Pourmalek F, Masoumi G, Sarvar M, Mahmoudabadi A, et al. Deadly rural road traffic injury: a rising public health concern in I.R. Iran. International journal of preventive medicine. 2014; 5(2):241-4. PMCID: PMC3950751 